\title{
GMR
}

\section{Molecular identification and genetic variation of varieties of Styphnolobium japonicum (Fabaceae) using SRAP markers}

\author{
R.X. Sun*, C.H. Zhang*, Y.Q. Zheng, Y.C. Zong, X.D. Yu and P. Huang \\ State Key Laboratory of Tree Genetics and Breeding, \\ Key Laboratory of Silviculture of the State Forestry Administration, \\ Research Institute of Forestry, Chinese Academy of Forestry, Haidian District, \\ Beijing, China \\ *These authors contributed equally to this study. \\ Corresponding author: Y.Q. Zheng \\ E-mail: zyq8565@126.com
}

Genet. Mol. Res. 15 (2): gmr.15027837

Received October 15, 2015

Accepted January 18, 2016

Published May 6, 2016

DOI http://dx.doi.org/10.4238/gmr.15027837

\begin{abstract}
Thirty-four Styphnolobium japonicum varieties were analyzed using sequence-related amplified polymorphism (SRAP) markers, to investigate genetic variation and test the effectiveness of SRAP markers in DNA fingerprint establishment. Twelve primer pairs were selected from 120 primer combinations for their reproducibility and high polymorphism. We found a total of 430 amplified fragments, of which 415 fragments were considered polymorphic with an average of 34.58 polymorphic fragments for each primer combination. The percentage of polymorphic fragments was $96.60 \%$, and four primer pairs showed $100 \%$ polymorphism. Moreover, simple matched coefficients ranged between 0.68 and 0.89 , with an average of 0.785 , indicating that the genetic variation among varieties was relatively low. This could be because of the narrow genetic basis of the selected breeding material. Based on the similarity coefficient value of 0.76 , the varieties were divided into four major groups. In addition, abundant and clear SRAP fingerprints were obtained and could be used to
\end{abstract}


establish DNA fingerprints. In the DNA fingerprints, each variety had its unique pattern that could be easily distinguished from others. The results demonstrated that 34 varieties of $S$. japonicum had a relatively narrow genetic variation. Hence, a broadening of the genetic basis of breeding material is necessary. We conclude that establishment of DNA fingerprint is feasible by means of SRAP markers.

Key words: Styphnolobium japonicum; SRAP; Molecular identification; Genetic variation; DNA fingerprints

\section{INTRODUCTION}

Styphnolobium japonicum L. Schott (syn. Sophora japonica L.) is a tree species belonging to the family Fabaceae. It is native to China and Korea, and is a source of timber, medicine, nectar, and ornamental material. It was formerly included within a broader interpretation of the genus Sophora (Käss and Wink, 1996; Santamour Jr and Riedel, 1997). Because it lacks the ability to form symbioses with rhizobia (nitrogen fixing bacteria) through the roots, it has been redefined as the genus Styphnolobium. It is also known as Chinese scholar tree or pagoda tree and has been cultivated for more than 3000 years in China. Owing to its potential values in pest and disease resistance, pollution tolerance, microclimate regulation, and high adaptability (Tang and Jiang, 2006), it is extensively used as a street tree. It has therefore been regarded as a city tree of Beijing, Xi' an, Dalian, Taian, and other cities in China.

During the last few decades, many new varieties of S. japonicum have been developed. This imposes new challenges for variety identification and protection of plant breeder's rights (PBR). The available morphological characteristics are limited in quantity and easily influenced by environmental factors, which means that they are time-consuming to measure, and therefore, have a limited application in variety identification (Tseng, 1962; Smith and Smith, 1989; Ma and Cai, 1996). In contrast, molecular marker technology based on genome DNA fingerprinting can overcome the disadvantages mentioned above (van de Wiel et al., 1999).

With rapid development of modern biotechnology, many molecular markers have been developed. Among them, sequence-related amplified polymorphism (SRAP) markers have been developed in Brassica species (Li and Quiros, 2001). These have several advantages over other markers, such as ease of use, reasonable throughput rate, high polymorphism, low cost, disclosure of numerous co-dominance loci, targeting open reading frames (ORFs), and easy isolation of bands for sequencing (Ren et al., 2004; Ai et al., 2011). Previous studies have shown that SRAP markers are evenly distributed in the genome, and could generate higher polymorphism than markers such as ISSR, RAPD, and SSR (Budak et al., 2004). SRAP markers have been used in genetic map construction (Gao et al., 2008), variety identification (Liu et al., 2008; Wu et al., 2010), and constructing DNA fingerprints in varieties, such as herbaceous peony (Guo et al., 2011), Porphyra lines (Qiao et al., 2007), turf-type Cynodon (Wang et al., 2009), and Hemarthria compressa "Guangyi" (Huang et al., 2014).

In this study, DNA fingerprints and dendrograms of $S$. japonicum were established using SRAP markers. The aim was to investigate molecular identification and genetic variation among varieties of $S$. japonicum, which may provide a scientific basis for breeding and utilization of these varieties. The goal was to apply DNA fingerprints using SRAP markers as a useful tool to provide evidence for protection of PBR in infringement cases. 


\section{MATERIAL AND METHODS}

\section{Plant materials}

Thirty-four varieties, including one sample tree of local S. japonicum in Fengtai of Beijing as a control material, were used in this study (Table 1). Trees of the different varieties were planted in a nursery located in the Fengtai District of Beijing. Three young compound leaves were collected from three sample trees for each variety and stored for DNA extraction.

\begin{tabular}{|c|c|c|c|}
\hline Abbreviation & S. japonicum variety name & Abbreviation & S. japonicum variety name \\
\hline CK & Local tree in Fengtai & CL7 & 'Clone 21' \\
\hline WS & 'Wuse' & CL8 & 'Clone 24' \\
\hline $\mathrm{JZ}$ & 'Golden stem' & CL9 & 'Clone 30' \\
\hline JY & 'Golden leaf' & CL10 & 'Clone 33' \\
\hline $\mathrm{LZ}$ & 'Pendula' & CL11 & 'Clone 34' \\
\hline LD & 'Liaohong' & CL12 & 'Clone 35' \\
\hline $\mathrm{C} 1$ & 'Caozhou 1' & CL13 & 'Clone 40' \\
\hline $\mathrm{C} 2$ & 'Caozhou 2' & CL14 & 'Clone 48' \\
\hline $\mathrm{C} 3$ & 'Caozhou 3' & CL15 & 'Clone 53' \\
\hline SJ & 'Shuangjimi' & CL16 & 'Sun 19' \\
\hline HD & 'Oligophylla' & CL17 & 'Sun 20 ' \\
\hline CL1 & 'Clone 2' & CL18 & 'Sun 27 ' \\
\hline CL2 & 'Clone 4' & CL19 & 'Wang 21' \\
\hline CL3 & 'Clone 12' & CL20 & 'Huang a' \\
\hline CL4 & 'Clone 13' & CL21 & 'Huang b' \\
\hline CL5 & 'Clone 18' & CL22 & 'Qingchao 1' \\
\hline CL6 & 'Clone 20' & CL23 & 'Guo 1' \\
\hline
\end{tabular}

\section{DNA extraction}

Total genomic DNA was extracted using the CTAB procedure (Murray and Thompson, 1980). The quality of the DNA samples was measured using an electrophoresis and imaging analysis system and the concentration was determined using a spectrophotometer Nanodrop 8000 (Thermo Scientific, Wilmington, NC, USA). Finally, the extracted DNA was diluted to a working concentration of $50 \mathrm{ng} / \mu \mathrm{L}$ and stored at $-20^{\circ} \mathrm{C}$ in a freezer.

\section{SRAP-PCR amplification}

In this study, a total of 120 SRAP primer combinations containing 10 forward primers and 12 reverse primers (Table 2) (Li and Quiros, 2001; Ahmad et al., 2004) were initially screened for polymorphism, using samples from four varieties. All primers were synthesized in Sangon Biotech Co. Ltd. (Shanghai, China). Preliminary optimization of SRAP-polymerase chain reactions (PCR) was performed as follows: $2 \mu \mathrm{L} 10 \mathrm{X}$ Taq buffer $\left(\mathrm{Mg}^{2+}\right.$-free), $0.30 \mathrm{mM}$ dNTP, 1.0 U Tap polymerase, $90 \mathrm{ng}$ DNA, $0.2 \mu \mathrm{M}$ of each primer, $2.0 \mathrm{mM} \mathrm{Mg}^{2+}$, and sterile double-distilled water to reach the total volume $20 \mu \mathrm{L}$. DNA amplifications were performed with an initial step at $94^{\circ} \mathrm{C}$ for $5 \mathrm{~min}$, which was followed by five cycles of $1 \mathrm{~min}$ at $94^{\circ} \mathrm{C}, 1$ min at $35^{\circ} \mathrm{C}$, and $1 \mathrm{~min}$ at $72^{\circ} \mathrm{C}$. The following 35 cycles included $94^{\circ} \mathrm{C}$ for $1 \mathrm{~min}, 50^{\circ} \mathrm{C}$ for $1 \mathrm{~min}, 72^{\circ} \mathrm{C}$ for $1 \mathrm{~min}$, and a final extension at $72^{\circ} \mathrm{C}$ for $10 \mathrm{~min}$, followed by final storage at $4^{\circ} \mathrm{C}$ (Li and Quiros, 2001). All the SRAP-PCRs were performed in the same thermal cycler (Bio-Rad, Miami, Florida, USA). The final PCR products were detected using a capillary electrophoresis analyzer (Qiagen, Dusseldorf, Germany). 
Table 2. Primer sequences used for the SRAP analysis.

\begin{tabular}{l|l|l|l}
\hline Primer code & Forward primers $\left(5^{\prime}-3^{\prime}\right)$ & Primer code & Reverse primers $\left(5^{\prime}-3^{\prime}\right)$ \\
\hline $\mathrm{Me} 1$ & TGAGTCCAAACCGGATA & Em 1 & GACTGCGTACGAATTAAT \\
\hline $\mathrm{Me} 2$ & TGAGTCCAAACCGGAGC & Em 2 & GACTGCGTACGAATTTGC \\
\hline $\mathrm{Me} 3$ & TGAGTCCAAACCGGAAT & Em 3 & GACTGCGTACGAATTGAC \\
\hline $\mathrm{Me} 4$ & TGAGTCCAAACCGGACC & Em 4 & GACTGCGTACGAATTTGA \\
\hline $\mathrm{Me} 5$ & TGAGTCCAAACCGGAAG & Em5 & GACTGCGTACGAATTAAC \\
\hline $\mathrm{Me} 6$ & TGAGTCCTTTCCGGTAA & Em6 & GACTGCGTACGAATTGCA \\
\hline $\mathrm{Me} 7$ & TGAGTCCAAACCGGTTG & Em 7 & GACTGCGTACGAATTCAG \\
\hline $\mathrm{Me} 8$ & TGAGTCCAAACCGGTCA & Em 8 & GACTGCGTACGAATTCCA \\
\hline $\mathrm{Me} 9$ & CGAATCTTAGCCGGATA & Em 9 & GACTGCGTACGAATTGCC \\
\hline & CGAATCTTAGCCGGAGC & Em10 & GACTGCGTACGAATTCA \\
\hline & & Em 11 & GACTGCGTACGAATTGAG \\
\hline & & Em12 & GACTGCGTACGAATTCAT
\end{tabular}

\section{Data analysis}

SRAP is a co-dominant marker. The capillary electrophoresis products were scored as " 1 " and " 0 ", where " 1 " indicated the presence of a specific allele and " 0 " indicated its absence, to generate a binary matrix. The similarity matrix and dendrogram were constructed using the numerical taxonomy multivariate analysis system (NTSYS-pc) v. 2.1 (Exeter Software, Setauket, NY) software package (Rohlf, 2000). A cluster analysis was first conducted, based on the similarity coefficients, using the unweighted pair group with arithmetic average (UPGMA) method with the SAHN module. The reliability of the dendrogram was then assessed by estimating the cophenetic correlation and comparing it with the similarity matrix, using the MxComp module of NTSYS-pc v. 2.1 (Rohlf, 2000). The result of this test was used to investigate how well the dendrogram represented the similarity data.

\section{RESULTS}

\section{Selection and analysis of SRAP primer combinations}

Twelve primer pairs were selected from 120 SRAP primer combinations, based on their reproducibility and polymorphism, to identify the 34 varieties of S. japonicum. The amplification fragment size mainly ranged between 100 and $2000 \mathrm{bp}$. A total of 430 amplified fragments were detected, out of which 415 fragments were considered polymorphic. For each primer combination, the number of polymorphic fragments averaged 34.58 , and ranged from 23 to 51 . The average percentage of polymorphic fragments was $96.60 \%$ and four primer pairs showed a polymorphism of $100 \%$ (Table 3 ).

\section{Construction of SRAP-DNA fingerprints for varieties}

The primer combination Em6-Me7 was used to construct SRAP-DNA fingerprints for the 34 varieties (Figure 1). During the construction of the DNA fingerprints, fragments less than $100 \mathrm{bp}$ were rejected, because they might be primer dimer. Polymorphic fragments were mainly distributed above $300 \mathrm{bp}$. Using the SRAP-DNA fingerprints, each of the varieties displayed its own unique fingerprinting pattern and could easily be distinguished from the others. By using the fingerprints, it was easy to identify whether a test sample was identical or similar to any of the 34 varieties. 
Table 3. Polymorphism amplified by SRAP primer combinations in 34 varieties.

\begin{tabular}{l|l|c|c|c}
\hline Code & Primer combination & No. of total fragments & No. of polymorphic fragments & Percentage of polymorphic fragments (\%) \\
\hline 1 & Me1-Em4 & 51 & 50 & 98.04 \\
\hline 2 & Me1-Em5 & 40 & 38 & 95.00 \\
\hline 3 & Me1-Em7 & 31 & 29 & 93.55 \\
\hline 4 & Me3-Em7 & 28 & 28 & 100.00 \\
\hline 5 & Me3-Em12 & 32 & 32 & 96.00 \\
\hline 6 & Me6-Em2 & 27 & 26 & 100.00 \\
\hline 7 & Me6-Em7 & 40 & 40 & 95.65 \\
\hline 8 & Me6-Em10 & 23 & 22 & 100.00 \\
\hline 9 & Me9-Em3 & 32 & 32 & 94.12 \\
\hline 10 & Me9-Em12 & 34 & 32 & 88.64 \\
\hline 11 & Me10-Em8 & 44 & 39 & 97.92 \\
\hline 12 & Me10-Em9 & 48 & 47 & 96.60 \\
\hline Total & & 430 & 415 & \\
\hline Average & & 35.83 & 34.58 & \\
\hline
\end{tabular}

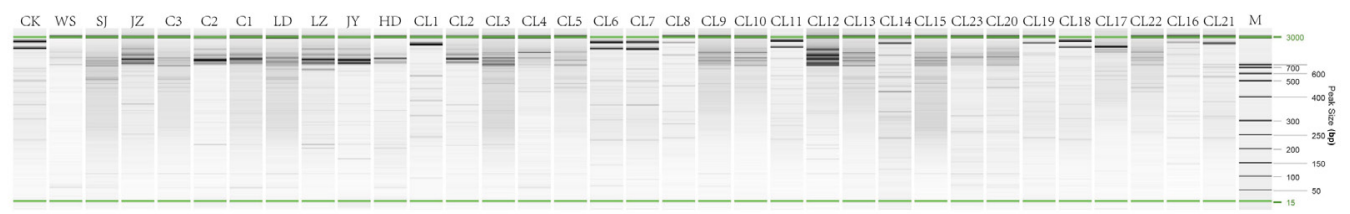

Figure 1. SRAP fingerprints of the Em6-Me7 primer combination for all varieties. Letters above the figure are the abbreviations of 34 varieties; numbers on the right side of the figure are the sizes (bp) of markers.

\section{Genetic variation and cluster analysis}

The differences among the 34 varieties of $S$. japonicum at the DNA level were determined by comparing their genetic similarity coefficients, according to the detected SRAP data. The genetic similarity coefficients were computed based on the proportion of shared fragments, and ranged from 0.68 to 0.89 , with an average of 0.785 . This indicated a narrow genetic basis and a high similarity among the varieties. A high similarity coefficient indicates a closer genetic relationship, and vice versa. The highest genetic similarity coefficient (0.89) was found between CL15 and CL16, and the lowest value was detected between CL9 and LZ. A dendrogram (Figure 2) was constructed based on the similarity matrix (data not shown).

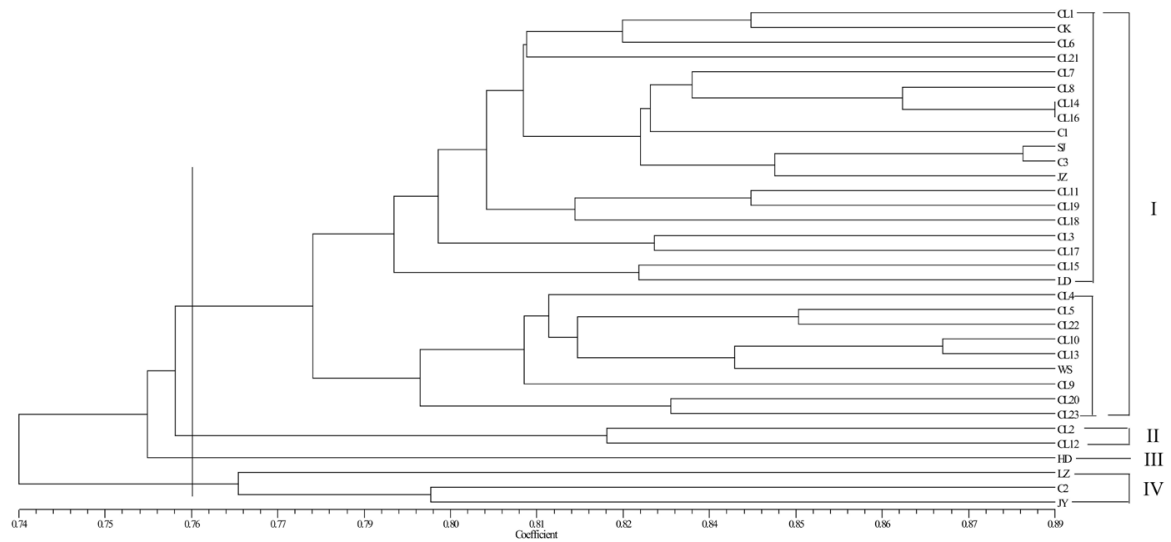

Figure 2. Dendrogram generated using the UPGMA method based on SRAP markers. 
The cophenetic correlation between the ultrametric similarities of the cluster tree and the similarity matrix was estimated at 0.80 , suggesting that the dendrogram well represents the similarity matrix. With a genetic similarity coefficient value of 0.76 , the 34 varieties were divided into four major groups. Group II included two varieties: CL2 and CL12; Group III included HD; Group IV consisted of three varieties: LZ, C2, and JY; the all other varieties were classified into Group I. Group I was further separated into two subgroups.

\section{DISCUSSION}

This is the first study focused on the molecular identification and genetic variation among 34 varieties of S. japonicum using SRAP markers. The similarity coefficients, ranging from 0.68 to 0.89 , demonstrated that the 34 varieties had a relatively low genetic variation. Therefore, it is necessary to broaden the genetic basis of breeding materials. The low genetic variation detected may be attributable to breeding and selection within a limited genetic basis over the long period of cultivation. However, it was evident that the percentage of polymorphic fragments was high $(96.60 \%)$, higher than in e.g. Robinia pseudoacacia L. (93.41\%) (Sun et al., 2009). The high polymorphism may be partially attributed to the large genetic differences among some of the varieties, as well as the advantages of the SRAP markers, such as high reproducibility, polymorphism, and suitability to amplify ORFs (Ai et al., 2011).

Compared to other varieties, the HD variety, also known as 'Wuyehuai', was separated into a single cluster, owing to large differences in leaf morphology compared to other varieties. The three varieties $\mathrm{C} 1, \mathrm{C} 2$, and $\mathrm{C} 3$ were clones developed from 153 plus trees selected throughout the Shandong province. They share many morphological characteristics but the cluster analysis revealed that $\mathrm{C} 1$ and $\mathrm{C} 3$ were closer to each other and both differed greatly from $\mathrm{C} 2$. This could likely be explained by differences in their geographic origins. Although it is difficult to distinguish $\mathrm{C} 1, \mathrm{C} 2$, and $\mathrm{C} 3$ based on morphological characteristics, they could be distinguished at the DNA level using the SRAP-DNA fingerprints based on the Em6-Me7 primer combination. A striking finding was that the LZ and JY varieties that are very distinct morphologically, clustered in a same group, indicating that the genetic distance between them was rather small. Further studies are needed to fully understand the underlying causes.

Compared with polyacrylamide gel electrophoresis, capillary electrophoresis is more effective and stable in detecting PCR products, which reduces human and system errors. Our findings indicate that SRAP markers are suitable for the analysis of genetic variation and molecular identification among varieties of S. japonicum, even for materials with a narrow genetic basis.

\section{Conflicts of interest}

The authors declare no conflict of interest.

\section{ACKNOWLEDGMENTS}

Research supported by the Special Fund for Public Interest (\#201204307) from the State Forestry Administration. We thank Yan He at Beijing Municipal Bureau of Landscape and Forestry and Xiaoman Xie at Shandong Forest Genetic Resources Center for their help in sample collection. 


\section{REFERENCES}

Ahmad R, Potter D and Southwick SM (2004). Genotyping of peach and nectarine cultivars with SSR and SRAP molecular markers. Amer. Soc. Hort. Sci. 129: 204-211.

Ai PF, Zhen ZJ and Jin ZZ (2011). Genetic diversity and relationships within sweet kernel apricot and related Armeniaca species based on sequence-related amplified polymorphism markers. Biochem. Syst. Ecol. 39: 694-699. http://dx.doi. org/10.1016/j.bse.2011.05.026

Budak H, Shearman RC, Parmaksiz I, Gaussoin RE, et al. (2004). Molecular characterization of Buffalograss germplasm using sequence-related amplified polymorphism markers. Theor. Appl. Genet. 108: 328-334.http://dx.doi. org/10.1007/s00122-003-1428-4

Gao LX, Liu N, Huang BH and Hu X (2008). Phylogenetic analysis and genetic mapping of Chinese Hedychium using SRAP markers. Sci. Hortic. (Amsterdam) 117: 369-377. http://dx.doi.org/10.1016/j.scienta.2008.05.016

Guo XF, Wang XH, Yu XY, Sun XZ, et al. (2011). Molecular identification and genetic variation of 13 herbaceous peony cultivars using SRAP markers. Acta Hortic. 918: 333-339.

Huang LK, Zhang Y, Zhang J, Zhang XQ, et al. (2014). Genetic stability and DNA ðngerprinting of the Hemarthria compressa cultivar "Guangyi". Biochem. Syst. Ecol. 55: 310-316. http://dx.doi.org/10.1016/j.bse.2014.03.027

Käss E and Wink M (1996). Molecular evolution of the leguminosae: Phylogeny of the three subfamilies based on $r b c \mathrm{~L}-$ sequences. Biochem. Syst. Ecol. 24: 365-378. http://dx.doi.org/10.1016/0305-1978(96)00032-4

Li G and Quiros CF (2001). Sequence-related amplified polymorphism (SRAP), a new marker system based on a simple PCR reaction: its application to mapping and gene tagging in Brassica. Theor. Appl. Genet. 103: 455-461. http:// dx.doi.org/10.1007/s001220100570

Liu LJ, Peng DX and Wang B (2008). Genetic relation analysis on ramie [Boehmeria nivea (L.) Gaud.] inbred lines by SRAP markers. Agric. Sci. China 7: 944-949. http://dx.doi.org/10.1016/S1671-2927(08)60133-9

Ma JH and Cai SQ (1996). Cultivation and processing of Porphyra yezoensis (vol. 1). Science Press, Beijing, 1-68.

Murray MG and Thompson WF (1980). Rapid isolation of high molecular weight plant DNA. Nucleic Acids Res. 8: 43214325.http://dx.doi.org/10.1093/nar/8.19.4321

Qiao LX, Liu HY, Guo BT, Weng ML, et al. (2007). Molecular identification of 16 Porphyra lines using sequence-related amplified polymorphism markers. Aquat. Bot. 87: 203-208. http://dx.doi.org/10.1016/j.aquabot.2007.06.006

Ren Y, Wang DY and Zhang YD (2004). Sequence-related amplified polymorphism (SRAP): a novel technique for molecular marker. Chin. Agric. Sci. Bull. 20: 11-13.

Rohlf FJ (2000). NTSYS-pc: Numerical Taxonomy and Multivariate Analysis System. Version 2.1 Exeter Software, Setauket, New York, USA.

Santamour Jr FS and Riedel LGH (1997). A new name for Sophora japonica. J. Arbori. 23: 166-167.

Smith JSC and Smith OS (1989). The description and assessment of distance between inbred lines of maize. II: The utility of morphological, biochemical, and genetic descriptors and a scheme for testing of distinctiveness between inbred lines. Maydica 34: 151-161.

Sun F, Yang MS, Zhang J and Gu JT (2009). ISSR analysis of genetic diversity of Robinia pseudoacacia populations. $J$. Plant Genet. Res. 10: 91-96.

Tang GM and Jiang WB (2006). Discussion on the Sophora plants and its application in the garden building and forestation. J. Anhui Agric. Sci. 34: 4577-4579.

Tseng CK (1962). The economic seaweeds in China (vol. 1). Science Press, Beijing, 105-107.

Wang ZY, Yuan XJ, Zheng YQ and Liu JX (2009). Molecular identification and genetic analysis for 24 turf-type Cynodon cultivars by Sequence-Related Amplified Polymorphism markers. Sci. Hortic. (Amsterdam) 122: 461-467. http:// dx.doi.org/10.1016/j.scienta.2009.05.031

van de Wiel C, Arens P and Vosman B (1999). Microsatellite retrieval in lettuce (Lactuca sativa L.). Genome 42: 139-149. http://dx.doi.org/10.1139/g98-119

Wu YG, Guo QS, He JC, Lin YF, et al. (2010). Genetic diversity analysis among and within populations of Pogostemon cablin from China with ISSR and SRAP markers. Biochem. Syst. Ecol. 38: 63-72. http://dx.doi.org/10.1016/j. $\underline{\text { bse.2009.12.006 }}$ 